\title{
Perspective of research on martensitic transformations: Present and future
}

\author{
K. Otsuka
}

\author{
National Institute for Advanced Interdisciplinary Research (NAIR), MITI, 1-1-4 Higashi, Tsukuba, \\ Ibaraki 305-8562, Japan
}

\begin{abstract}
Substantial progress has been made recently on the study of martensitic transformations both in fundamentals and in applications. These recent developments are briefly reviewed and future directions are suggested. It will been shown that this is still quite a promising field for research in materials science and engineering.
\end{abstract}

As is well-known, the martensitic transformation is a typical cooperative phenomenon in solids. Thus, macroscopic shape change appears upon transformation, although the displacements of each atom is small. As a result, unique properties appear such as the shape memory effect (SME) and superelasticity (SE), the rubber-like behavior (RLB) etc., and keen attention is being paid on shape memory alloys (SMA) as new functional materials or smart/intelligent materials, which already exist. Similarly, much progress has recently been made on the fundamental aspects of martensitic transformation (MT), such as the kinetics of MT (i.e. athermal vs. isothermal), origin of martensite aging, and the RLB, premartensitic behavior etc. In the present paper we review these recent developments and try to suggest the direction for further works. The choice of the topics depends partly on the taste of the authors, and it is not exhaustive because of the space limitation. The author hopes that this short review will be useful to stimulate future works of this important area, despite the fact of non-exhaustiveness.

\section{Origin of martensitic transformations}

As stated earlier, the martensitic transformation is a diffusionless cooperative phenomenon in solids, which is quite unique. Thus, there are many papers on the general mechanism of the transformation such as the phenomenological crystallographic theory or Landau-Ginzburg theory to account for the transformation from general point of view. On the other hand, it is quite surprising to notice that the paper on the origin of MT is quite rare[1,2]. Here "origin" means a driving force for MT. One reason for this may be due to the diversity of MT, for which the driving force may not be ascribed to a single source, as will be discussed later. Second reason may lie in the fact that the most important characteristics of MT lie in the mechanism (i.e. the way of transformation in a diffusionless manner), and not in the driving force. Even so, the search for the driving force of each MT will be important.

In our simple-minded opinion, the driving force for MT may be divided into two. The first originates in the entropy term in a free energy due to lattice (or atoms). The second is the electronic origin, which includes magnetic origin, since magnetic properties also originate from electronic structure. Most of the $B$ phase alloys belong to the first class. Since BCC has a large entropy, this structure is favored at high temperatures. This is especially true when e/a (electron concentration) of the alloy is close to 1.5 (, which is usually the case in B-phase alloys), since the nesting of the Fermi surface occurs at the Brillouin zone to stabilize the electronic structure. However, when temperature is lowered, the entropy term in the free energy becomes insignificant. Thus, the MT occurs from BCC (and/or ordered BCC) to close-packed stacking ordered structures which have lower internal energy than BCC. This explains most of the MT in B-phase alloys, although there are some exceptions. In the case of B2- $\zeta 2$ ' transformation in $\mathrm{Au}-\mathrm{Cd}$ and $\mathrm{B} 2-$ $\mathrm{R}$ transformation in Ti-Ni, the volume change upon MT is positive (even though the magnitude is small), thus they can not be classified in the first class. Thus, the origin must be electronic. This is discussed by Kakeshita et al.[2] recently. In the familiar MT in ferrous alloys, the volume change is positive, and thus the origin is usually believed to be magnetic. However, ferromagnetism and antiferromagnetism originate 
from the band structure of the alloys. Thus, the present case may be classified in the second case. The FCC-FCT transformations in In-Tl, Mn-Cu, Fe-Pd and Fe-Pt are possibly classified in the second class, although more detailed studies are required. Anyway we believe the studies in this direction are important in the near future.

\section{Premartensitic phenomena}

As described in the previous section, MT is a cooperative phenomenon in solids. Thus, behavior of elastic constants and phonons are important. After the suggestion by Zener[3], extensive studies have been done on premartensitic phenomena and the softening in $c^{\prime}$ with decreasing temperature, which represents the resistance for $\{110\}<110>$ shear, was found in various B-phase alloys, along with the softening in some specific phonon modes, and tweed[4,5] etc. In these studies attention was paid to the softening in $\mathrm{c}^{\prime}$ and corresponding TA2 phonon mode in phonon branch. Recently we[6-10] carried out a systematic work on the measurement of elastic constants of various $\mathrm{Ti}-\mathrm{Ni}-\mathrm{X}(\mathrm{X}=$ none, $\mathrm{Cu}, \mathrm{Fe})$ based alloys. In the alloy system, three distinct types of MT occurs, i.e. B2-B19'(monoclinic) (in solution-treated Ti-Ni), B2-B19 (orthorhombic) (in Ti-Ni-Cu) and B2-R (trigonal) (in Ti-Ni-Fe and aged Ti-Ni). We could correlate each distinct transformation with a different elastic constant behavior. In this alloy system, both $\mathrm{c}^{\prime}$ and $\mathrm{c}_{44}$, which represents the resistance for $\{001\}<100>$ shear, softens with decreasing temperature, and the magnitude of $\mathrm{c} 44$ is about $1 / 2$ or $1 / 3$ smaller than those of ordinary materials, thus the anisotropy factor $A=$ $\mathrm{c} 44 / \mathrm{c}^{\prime}$ is as small as 2-3. This may be one reason for the ductile nature of Ti-Ni alloy system. We[6] pointed out that the softening in $\mathrm{c}^{\prime}$ alone can not explain the creation of the monoclinic $\mathrm{B} 19^{\prime}$, and that the softening in $\mathrm{c} 44$ facilitates to create the monoclinic $B$-angle, since $\mathrm{c} 44$ represents the resistance for $\{001\}<110>$ shear as well. Furthermore, we found that the anisotropy factor A decreases with decreasing temperature for solution-treated $\mathrm{Ti}-\mathrm{Ni}$, while $\mathrm{A}$ increases with decreasing temperature for $\mathrm{Ti}-\mathrm{Ni}-\mathrm{Cu}$ alloy. This means that coupling occurs between $\{110\}<110>$ shear and $\{001\}<110>$ shear for the former, while decoupling occurs for the latter. Thus, they could correlate the respective transformation and the corresponding elastic constants behavior. This is an important result showing the importance of not only $\mathrm{c}^{\prime}$ but also of $\mathrm{c}_{4} 4$ in MT.

Planes et al.[11,12] found that $c^{\prime}$ takes a constant value at Ms temperature irrespective of the composition for Cu-based alloys. Similarly we[13] found that the same applies to the B2-R transformation in Ti-Ni based alloys. We[14] further reported that this can be explained by applying Landau theory, if the transformation involves $\{110]<110>$ type shear and shuffle only.

Recently Barsch[15] carried out a rigorous Landau-Ginzburg treatment for all MT in Ti-Ni-X and could explain them all, except for R-B19' transformation, for which B19' phase is not a sub-group of R-phase. Furthermore, he supported the above mentioned view on the role of c44 to the MT in Ti-Ni-based alloys.

The future work on premartensitic phenomena will be to critically compare various premartensitic phenomena (e.g. softening, central peak, diffuse scattering, tweed etc.) obtained by various techniques and to deduce a further unified view.

\section{Electronic structures of martensites}

By the rapid progress of computers in recent years, it is now possible to calculate electronic structures (i.e. band structures) of martensites by utilizing first principles calculations. Such calculations have actually been done in detail for B2-B19' and B2-R transformations in Ti-Ni-based alloys[16,20], B2- $\zeta 2^{\prime}$ (trigonal) transformation in $\mathrm{Au}-\mathrm{Cd}$ alloy[21], and $\mathrm{B} 2-14 \mathrm{M}$ transformation in $\mathrm{Ni}-\mathrm{Al}$ alloy[22]. In the phenomenological crystallographic theory such as Wechsler-Lieberman-Read theory and BowlesMackenzie theory, accurate lattice parameters are required but atomic parameters exhibiting atom positions are not required. However, in the electronic structure calculations, the accurate atomic parameters are most important. Both Ye et al.[18] and Sanati et al.[19] reported that the atomic parameters reported by Kudoh et al.[23] for $\mathrm{B}^{\prime} 9^{\prime}$ martensite in a $\mathrm{Ti}-\mathrm{Ni}$ alloy, which was determined by single crystal $\mathrm{x}$-ray diffraction method, gives the lowest energy among those reported by various researchers. 
These electronic structure calculations will become important in relation with the origin of MT in Section 1 and in the study of martensitic transformation vs. magnetism in Section 4. For that purpose the accurate determination of atomic parameters of each martensite becomes important, and such study should be encouraged.

\section{Martensitic transformations and magnetism}

Shape memory alloys are attracting much attention recently as smart or intelligent materials, which will be discussed in Section 11. However, one shortcoming of SMA is a rather slow actuation speed, since SME is driven by conduction of heat. However, if the effect is driven magnetically, the speed will become much faster. From this reason shape memory materials (SMM), which exhibit magnetic transition simultaneously, are attracting much attention recently. $\mathrm{Ni2} \mathrm{MnGa}$ is one of such materials, and Ullakko et al.[24] showed that the alloy (or compound) exhibit the giant magnetostriction as large as $0.2 \%$. He further suggested that the magnetostriction is due to the reversible movement of twin boundaries, since each twin variant has their own magnetization. Similar works are being done for Fe-30at\%Pd[25], $\mathrm{Fe}_{3} \mathrm{Pt}[26]$ and $\mathrm{Fe}-\mathrm{Ni}-\mathrm{Co}-\mathrm{Ti}$ [26]alloys, and the magnetization of $0.5 \%$ is being reported for $\mathrm{Fe}_{3} \mathrm{Pt}$ alloy[26]. Such work will be expanded further. The relation between MT and magnetism will also be important to identify one of the driving forces of MT.

\section{Kinetics and thermodynamics of martensitic transformations}

Recently Kakeshita et al.[27] proposed a statistical thermodynamic theory to account for both athermal and isothermal MT in a unified manner, which have been thought to be distinct to each other. According to the theory, the probability to nucleate a martensite is determined by the probability that a group of atoms overcome the energy barrier for nucleation, and the probability is proportional to the Boltzman factor. If the energy barrier is finite, the transformation becomes isothermal, while if it is zero, the transformation becomes athermal. The theory predicts the following three important results.

1) For ferrous alloys, if magnetic field is applied, the incubation period becomes shorter, and if the field is large enough, the isothermal transformation may change into athermal one.

2) For ferrous alloys, for which the volume change upon transformation is positive, the incubation period becomes longer by the application of hydrostatic pressure. Furthermore, if the hydrostatic pressure is high enough, athermal transformation may change into isothermal one.

3) Even in alloys, which exhibit athermal transformations, isothermal transformation may appear, if they are held at a temperature above $\mathrm{Ms}$ and below $\mathrm{T}_{0}, \mathrm{~T}_{0}$ being the equilibrium temperature between parent and martensite.

All the predictions were confirmed by experiments, and the above proposition was justified[1,28]. Especially, with respect to Prediction 3, isothermal transformations were found above $\mathrm{Ms}$ in $\mathrm{Fe}-\mathrm{Ni}$, $\mathrm{Cu}-\mathrm{Al}$ $\mathrm{Ni}, \mathrm{In}-\mathrm{Tl}[29]$ and $\mathrm{Na}[30]$ alloys and metal. However, recently, the present authors[31] obtained the opposite result in furnace-cooled Ti-50at\% Ni alloy, which exhibits $\mathrm{B} 2-\mathrm{B} 19^{\prime}$ transformation. The specimen was held at a temperature $\Delta T=1.6 \mathrm{~K}$ above $\mathrm{Ms}$ for 21 days, but no isothermal transformation was observed. In this experiment, the alloy was chosen such that no diffusion, which may complicates the transformation, is allowed, and the holding temperature was chosen so close to Ms in order to make the energy barrier as small as possible. However, the result was negative. The result may mean that there may be some other factors which we do no know in the above theory. To clarify the above points, similar works should be done for other various alloys without diffusion problem.

\section{Interaction of point defects with martensitic transformations}

Lattice defects such as point defects and dislocations are inevitable in crystals, and it is well-known that such defects greatly affect mechanical, electrical etc. properties of crystals. Even for MT, the effect of 
dislocations has been known pretty well, but the effect of point defects has not attracted much attention. It seems to the author that we are now in the time to study the effect systematically and extensively.

There has been a long-standing puzzling problem of "the rubber-like behavior" and "martensite aging effect" in thermoelastic martensite such as in $\mathrm{Au}-\mathrm{Cd}, \mathrm{Au}-\mathrm{Cu}-\mathrm{Zn}, \mathrm{In}-\mathrm{Tl}$ etc. i.e. when the alloys are aged in the martensitic state for some time, the alloys become pseudoelastic upon unloading, without accompanying phase transformation. This is the rubber-like behavior[32-36]. Similarly, the Af temperatures of the same alloys increase with increasing aging time. This is the "martensite aging effect"[32-36]. Both phenomena were recently explained by the present authors by "SymmetryConforming Short Range Order (SC-SRO) Principle"[37], which states that the distribution of point defects such as vacancies, solutes and ASD (Anti-Structure Defect) follows the symmetry of the crystal. Furthermore, they predicted three new phenomena based on SC-SRO principle as follows.

1) When aged martensite is reverse transformed by heating, the TEM contrast of martensite ( due to twins) remains for some time, and fades away with aging in the parent phase.

2) Microstructure memory: when the aged martensite is reverse transformed by heating, and the immediately transform back again to martensite by cooling, the same microstructure will appear due to SCSRO principle.

3) Two-way shape memory effect: due to microstructure memory described above, the two-way SME is expected to appear for aged martensite.

These predictions have been recently confirmed by experiments[38]. i.e. Various phenomena such as RLB, martensite aging effect, TEM contrast effect, microstructure memory and the two-way SME were all explained by a unified principle of SC-SRO. In order to discuss the effect of point defects, the density of such defects must be evaluated. For that purpose, we[39] proposed a theory on the formation of point defects in B2 type ordered lattice.

Although the effect of point defects on MT is rather subtle, we are now in a stage to explore such problems.

\section{R-phase transformation}

$B 2-R$ phase transformation is quite a unique transformation, and much work has been done. Due to extensive work by Salamon et al.[40], the transformation was believed to proceed in the following way until recently: B2-Incommensurate Phase at Rs (the temperature at which resistivity starts to increase)- Rphase (commensurate Phase). However, it became clear by recent TEM observations that the transformation proceeds in the following way[41]: the parent B2 phase is already accompanied by diffuse incommensurate spots at temperature above $\mathrm{Rs}$ for a wide temperature range (i.e. more than $30 \mathrm{~K}$ ). It transforms into R-phase (,which is commensurate) at Rs, and the two phases coexist between Rs and Rf (R-phase finish temperature). Recently, Murakami and Shindo[42] observed an interesting premartensitic behavior at temperatures above Rs by energy-filtered TEM technique. i.e. They observed that incommensurability decreases with decreasing temperature, and R-phase nuclei (?) nucleate and grow with decreasing temperature. More work is necessary including $x$-ray diffraction technique to understand premartensitic behavior.

\section{Structure of irrational twin boundary (Type II twin)}

In some alloys such as Ti-Ni, Cu-Al-Ni, Cu-Sn etc., Type Il twinning occurs as a lattice invariant shear, in which twin plane has irrational indices[43]. Christian[44] argued the irrationality on a microscopic scale, and proposed that the irrational boundary consists of rational ledges and steps. Knowles[45] reported some observations to support it for Ti-Ni alloys, but could not observe in a critical orientation described below. For $\mathrm{Cu}-\mathrm{Al}-\mathrm{Ni}$ martensite, Hara et al.[46] observed the irrational boundary in a unique orientation of $\eta 1$ (twinning shear direction), for which electron beam is parallel to the irrational twin boundary. However, they could not observe neither ledges nor steps. Instead they observed a rather wide strain 
contrast at the boundary, which means that the boundary is microscopically accommodated in a wide area rather than a sharp boundary. Nishida et al.[47] also made the similar observations for Ti-Ni alloys by using the unique $\eta 1$ orientation.

More recently Nishida et al.[48] observed the irrational twin boundary in Ti-Pd martensite for both quenched- and furnace-cooled samples. As a result, they did not observe neither ledges nor steps for quenched samples, but observed them for furnace-cooled samples. Thus, they concluded that the irrational boundaries formed by MT directly is irrational even on a microscopic scale, but those annealed at high temperatures consist of rational ledges and steps due to thermal effect.

\section{Ti-Ni thin films}

The technology trends are now for microfabrications. Thus, SMA films are attracting much attention. There are two ways to prepare thin films: sputter deposition and melt-spinning. In the case of sputter deposition, films are usually deposited in an amorphous state on cold substrate. The grain size can be submicron, and thus the production of thin films with good mechanical properties are possible. Generally speaking, microstructure, transformation and SME characteristics of Ti-Ni thin films are the same as those in bulk $[49,50]$, except for Ti-rich Ti-Ni alloys. In the latter, precipitation hardening can not be used in bulk state, since the phase boundary of Ti-Ni phase is vertical. On the contrary, thin films are sputter deposited in amorphous state, and thus Ti-rich precipitates are available upon crystallization and /or suitable heat-treatments[51-53]. Two types or more (if shapes are also taken into account) precipitates are known: Ti2 Ni phase and plate-like precipitates like G.P. zone. The plate-like precipitates are known to be especially effective to increase strength[52].

Although sputter deposited films have many advantages described above, one disadvantage is the high cost and low fabrication rate, since very high vacuum is required and, and it will take about 2 hs for sputter deposition to make a film. In that respect, melt-spinning technique may be more attractive, if columnar nature of the grains are improved. It is now anticipated that some applications of thin films will appear soon.

\section{The nature of reversible change in Ms temperature by heat-treatment}

In Ti-Ni alloys, lat\% change in composition induces the change in Ms by more than $100 \mathrm{~K}$. Thus, the control of Ms is vital in the actual production of SMA. Horikawa et al.[54] found a very simple and effective way to control Ms, just by changing annealing temperature by short time flash annealing. By that technique, they could obtain reproducible Ms by cyclic test. They attributed the effect due to reversion of precipitates. Recently, however, Zhang et al.[55] found that the same change in Ms can be obtained by long time annealing as well. Furthermore, they confirmed by TEM observations that the effect is due to the solubility change in the matrix. See Ref.[55] for more details.

\section{Smart/intelligent materials}

Smart/intelligent materials are becoming very popular these days to achieve safety and miniaturization of devices. They are typically defined as those materials which have sensor and actuator functions simultaneously, but they are used in a more loose manner. In that respect, SMA are those which already exist. As such applications, composites consisting of SMA and polymer for vibration control[56], and those consisting of SMA and metal (or polymer) for strengthening may be useful[57]. Correlation of electrical resistivity vs. transformation will also be useful for such purposes[58]. Anyway we should utilize such opportunity in recent trends.

In addition to the above, medical applications such as guide wires and stents are becoming a big business. See Ref.[59] for more details. 


\section{Acknowledgments}

The author is grateful to T.Suzuki, T.Ohba, X.Ren, T.Kakeshita, D.Shindo, and Y.Murakami for useful discussions in preparing the present manuscript. The present work was supported by "Research for Future" of Japan Society for Promotion of Science (JSPS) (1998-2002).

\section{References}

1. F.E.Wassermann, J.Kästner, M.Acet, P.Entel, in Proc.Int.Conf. on Solid-Solid Phase Transformations'99, Kyoto,1999, ed.M.Koiwa, K.Otsuka, T.Miyazaki(Jpn.Inst.Metals, 1999), p.807.

2. T.Kakeshita, T.Fukuda, T.Saburi, Science and Technology of Advanced Materials, 1, 63(2000).

3. C.Zener, Phys.Rev.71, 846(1947).

4. N.Nakanish, Prog.Mater.Sci.,24, 143(1980).

5. D.Schryvers, in Proc.First Int.Alloy Conf.,Athens,1996,ed.A.Gonis,A.Meike,P.Turchi(Plenum Publ.Corp.,1996), p.321.

6.X.Ren, K.Otsuka, Scripta Mater.,38,1669(1998).

7.X.Ren, K.Taniwaki, K.Otsuka, T.Suzuki,K.Tanaka,Yu.I.Chumlyakov,T.Ueki,Philo.Mag.,A75, 31(1999).

8.X.Ren,N.Miura,K.Otsuka,T.Suzuki,K.Tanaka,Yu.I.Chumlyakov,M.Asai,Mater.Sci.Eng.,A273275,190(1999).

9. J.Zhang, X.Ren, K.Otsuka, K.Tanaka, Yu.I.Chumlyakov, M.Asai, Mater.Trans.JIM, 40, 385 (1999).

10. N.Miura, J.Zhang, X.Ren, K.Otsuka, T.Suzuki, K.Tanaka, Yu.I.Chumlyakov, M.Asai, in Proc. Int.Conf. on Solid-Solid Phase Transformations'99, Kyoto, 1999, ed.M.Koiwa, K.T.Miyazaki (Jpn.Inst.Metals, 1999), p.827.

11. A.Planes, Ll.Manosa, D.Rios-Jara, J.Ortin, Phys.Rev.45B, 7633(1992).

12. Ll.Manosa, M.Jurado, A.Planes, J.Zarestky, T.Lograsso, C.Stassis, Phys.Rev.49B, 9969 (1994).

13. X.Ren, N.Miura, J.Zhang, K.Otsuka, K.Tanaka, M.Koiwa, T.Suzuki, Yu.I.Chumlyakov, M.Asai, Mater.Sci. Eng., submitted (April,2000).

14. X.Ren, K.Otsuka, in Proc.Int.Symp. on Shape Memory Materials (SMM'99), Kanazawa, 1999, ed. T.Saburi (Trans Tech Publications, 2000), p.429.

15. G.R.Barsch, in Proc.Int.Symp. on Shape Memory Materials (SMM'99), Kanazawa, 1999, ed. T.Saburi(Trans Tech Publications, 2000),p.367.

16. S.E.Kulkova, V.E.Egorshukin, V.V.Kalchikhin, Solid State Communications, 77, 667(1991).

17. G.L.Zhao, B.N.Harmon, Phys.Rev.B48, 2031(1993).

18. Y.Y.Ye, C.T.Chan, K.M.Ho, Phys.Rev.B56,3678(1997).

19. M.Sanati, R.C.Albers, F.J.Pinski, Phys.Rev.,B58,13590(1998).

20. T.Fukuda, T.Kakeshita, H.Houjyou, S.Shiraishi, T.Saburi, Mater.Sci.Eng.,A273-275, 166 (1999).

21. T.Kakeshita, T.Saburi, in Proc.Int.Conf. on Solid-Solid Phase Transformations'99, Kyoto, 1999, ed.M.Koiwa, K.Otsuka, T.Miyazaki (Jpn.Inst.Metals, 1999), p.907.

22. S.C-.Liu, J.W.Davenport, E.W.Plummer, D.M.Zehner, G.W.Fernando, Phys.Rev.B42, 1852(1990).

23. Y.Kudoh, M.Tokonami, S.Miyazaki, K.Otsuka, Acta metall.,33, 2049(1985).

24. K.Ullakko, J.K.Huang, V.V.Kokorin, R.C.OHandley, Appl.Phys.Lett.,69,1966(1996).

25. R.D.James, M.Wuttig, Philo.Mag.,A77, 1273(1998).

26. T.Kakeshita, T.Takeuchi, T.Fukuda, T.Saburi, R.Oshima, S.Muto, K.Kishio, Mater.Trans. JIM, in press (2000).

27. T.Kakeshita, K.Kuroiwa, K.Shimizu, T.Ikeda, A.Yamagishi, M.Date, Mater.Trans.JMM, 34, 423(1993).

28. T.Kakeshita, T.Saburi, K.Shimizu, Mater.Sci.Eng.,A273-275,21(1999).

29. H.Abe, M.Ishibashi, K.Oshima, T.Suzuki, Phys.Rev.,B50, 9020(1994).

30. H.Abe, K.Oshima, T.Suzuki, S.Hoshino, Phys.Rev.,B49,3793(1994).

31. A.Takeda, X.Ren, K.Otsuka, presented at Annual Fall Mtg. of Jpn.Inst.Metals, Kanazawa, 1999, Collected Abstracts, p.378.

32. K.Otsuka, C.M.Wayman, Pseudoelasticity and stress-induced martensitic transformations, Review on the Deformation Behavior of Materials (Freund Publ. House, Israel,1977), Vol.2,p.81.

33. M.Ahlers, G.Barcelo, R.Rapacioli, Scripta Metall.,12,1075(1978). 
34. K.Marukawa, K.Tsuchiya, Scripta Metall.,32,77(1995).

35. T.Suzuki, T.Tonokawa, T.Ohba, J. de Phys.III,5, C8-1065(1995).

36. X.Ren, K.Otsuka, Phase Transitions, 69, 329(1999).

37. X.Ren, K.Otsuka, Nature, 389, No.6651, 579(1997).

38. X.Ren, K.Otsuka, Phys.Rev.Lett., in press (2000).

39. X.Ren, K.Otsuka, Philo.Mag.,A80, 467(2000).

40. M.B.Salamon, M.E.Meichle, C.M.Wayman, Phys.Rev.,B31,7306(1985).

41. T.Tamiya, D.Shindo, Y.Murakami, Y.Bando, K.Otsuka, Mater.Trans.JIM, 39, 714(1998)

42. Y.Murakami, D.Shindo, Science and Technology of Advanced Materials, in press $(2000)$.

43. K.Otsuka, Mater.Sci.Forum, 56-58,317(1990).

44. J.W.Christian, A.G.Crocker, Dislocations in Solids, ed. F.R.N.Nabarro (North Holland,1980), Vol.3,p.217.

45. K.M.Knowles, Phil.Mag.,A45, 357(1982).

46. T.Hara, T.Ohba, K.Otsuka, in Proc.3rd Pacific Rim Int. Conf. on Advanced Mater.Processing (PRICM3), Hawaii, 1998, ed.M.A.Imam, R.DeNale, S.Hanada, Z.Zhong, D.N.Lee (TMS,1998) ,p.1199.

47. M.Nishida, K.Yamauchi, I.Itai, H.Ohgi, A.Chiba, Acta metall.mater.,43,,1229(1995).

48. S.Ii, M.Nishida, K.Hiraga, in Proc.Int.Conf. on Solid-Soli Phase Transformations, Kyoto, 1999, ed.M.Koiwa, K.Otsuka, T.Miyazaki (Jpn.Inst.Metals, 1999), p.1096.

49. S.Miyazaki, A.Ishida, Mater.Sci.Eng.,A273-275,106(1999).

50. A.Gyobu, Y.Kawamura, H.Horikawa, T.Saburi, A273-275, 106(1999).

51. Y.Nakata, T.Tadaki, H.Sakamoto, A.Tanaka, K.Shimizu, J.Phys.IV(France)Suppl.III,5,C8-671(1995).

52. S.Kajiwara, T.Kikuchi, K.Ogawa, T.Matsunaga, S.Miyazaki, Phil.Mag.Lett.,74,137(1996).

53. A.Ishida, K.Ogawa, M.Sato, S.Miyazaki, Metall.Mater.Trans.,28A,1985(1997).

54. H.Horikawa, H.Tamura, Y,Okamoto, H.Hamanaka, F.Miura, in Proc.MRS Int.Mtg. on Advanced Mats.,9(1989), p.195.

55. J.Zhang, W.Cai, X.Ren, K.Otsuka, M.Asai, Mater.Trans.JIM, 40, 1367(1999).

56. L.McD.Schetky, MRS Symp.Proc.,246(1999),p.299.

57. Y.Furuya, J.Tani, Mater.Sci.Forum, 327-328,91(2000).

58. M.Pozzi, G.Airoldi, Mater.Sci.Eng.,A273-275,300(1999).

59. T.Duerig, A.Pelton, D.Stöckel, Mater.Sci.Eng.,A273-275,149(1999). 